\title{
Fields of Vision: Arts and Sport Communities and Methods of Practice
}

\author{
By Lisa Stansbie*
}

\begin{abstract}
The disciplines of arts and sport are usually divided in education, research, professional practice and cultural policy, even though in the UK they both lie within a single department of Government (Department for Digital, Culture, Media and Sport). In the UK the relationship between arts and sports can sometimes appear awkward, with the two disciplines often only bought together for large international mega sporting events. However, links between the arts and sport can enhance strategies to increase participation in each and promote cultural citizenship, stimulate experimentation, innovation and tackle challenging topics. This paper takes The Fields of Vision Project and the associated Fields of Vision Manifesto as a departure point to propose pioneering modes of practice that cross the discipline boundaries of sports and art, whereby a dialogue and community of practice develops that encourages audience diversity, community engagement and hybrid forms of practice. Utilising precedents from contemporary visual art, propositions are expressed for new experiences and opportunities for practitioners, producers and audiences that might offer impact and legacy beyond the mega sporting event.
\end{abstract}

Keywords: Art, Community, Culture, Olympics, Sport.

\section{Introduction}

Collaboration and cross-disciplinary working between practitioners and participants in the fields of arts ${ }^{1}$ and sport can open up innovative spaces for experimentation, innovation and create new audiences. Links between the two can increase participation in both and also a new space can emerge whereby art and sport are transdisciplinary.

The practice and experience of both disciplines as a participant and audience offers opportunity for new experiences and engagement internationally and locally. The promotion of access to enable participation in both within the UK falls under the remit of the government's department for Digital, Culture, Media and Sport (DCMS $)^{2}$ with a proposed focus on participation and wellbeing:

"Everyone should be able to access and participate in the arts, heritage and sport no matter what their background or where they come from. Participation in many DCMS sectors is proven to increase health and well-being, enrich citizens' lives and promote social mobility through broadened experiences and networks. Arts

\footnotetext{
*Dean, Leeds School of Arts, Leeds Beckett University, UK.

'AArts' in this paper is used as a broad term to include visual art, dance, literature, poetry, performance and music.

${ }^{2}$ DCMS is a ministerial department in the UK, supported by 46 different public bodies and agencies.
} 
and culture, heritage, libraries, museums and galleries and sport all have a vital role to play in this work and we believe no-one should be left behind." (DCMS 2016)

While the two disciplines sit within the same UK government department, currently there is very little collaboration whereby the two areas are truly working together. Projects where sports and arts convene, are usually attached to large sporting events. In this way arts and sport are bought together for events such as the Olympics (Cultural Olympiad), Commonwealth Games, The Tour de Yorkshire, The Tour de France, The FIFA World Cup and the ICC Cricket World Cup. Such events provide a unique opportunity for the host nation to highlight their cultural and sporting heritage. However, despite the prominence of these high-profile arts and sport projects, they rarely have a legacy of impact and a life beyond the timescale of the sports event.

It should be noted that the notion of bringing the two areas closer together is not a contemporary idea. Pierre de Coubertin, founder of the International Olympic Committee (and an educator) was particularly interested in the notion of physical and intellectual education being equally important, identifying a parity across sports and arts. This concept arose from his research around the ancient Greek gymnasium schooling whereby he saw evidence of a range of individuals working both practically and theoretically across different subjects. Ultimately this led to him reviving the ancient Olympic Games into a modern format. Interestingly de Coubertin's early ideas are described as being centred on the ability of International games to potentially broaden understanding across cultures and also promote and encourage amateur sportspersons rather than professional athletes. ${ }^{3}$ This notion of expanding the audience and participants of sports is common today. De Courbertin was also responsible for starting the art competitions as part of the Olympics, which ran from 1912 to 1948 (Neuendorf 2016). The art competition in this format included different categories that artists could compete in and win medals: painting, sculpture, architecture, music and literature. While these early competitions could be seen from a contemporary perspective as conceptually limited, due to the fact that artists were tasked with illustrating and responding to specific sports (and architecture for example was focused on the design of stadiums and sports facilities) it is an example of a consideration (stemming from the ancient Greek ideals of a move toward the dual importance of both) of an early approach that attempted to draw the two areas together around a single focused event. However, these early attempts to draw together the two areas, did so less successfully, always retaining the distinctive boundary of each discipline, as defined by the Olympics of the time.

Research has shown that the idea of an Olympiad (Cultural events in the lead up to an Olympic Games) stems back to the ancient Greek games. It is thought that the first Olympiad started around the Hellenistic period. In the contemporary Olympic Games the original notion of Coubertin's art and sport balance has shifted significantly with the Cultural Olympiad replacing the notion of an art competition and the host country's cultural programme in the

${ }^{3}$ It should be noted that some of Coubertin's definitions of 'amateur' were very much flavoured by his personal views on class. 
lead up to and during the games featuring now as a prerequisite from the IOC (International Olympic Committee).

In the 2012 UK Olympics the Cultural Olympiad had a prominent place in the preceding years ${ }^{4}$ and it appeared that the UK had moved some way toward achieving the IOC remit of encouraging a blending of the two disciplines. The IOC states that the Cultural Olympiad is a '...required element of any Olympic and Paralympic Games and is part of the International Olympic Committee's ambition to present the Games as the blending of 'sport, culture and education' (Garcia 2013).

While previous government initiatives have suggested the benefits of both arts and sport participation, there currently does not exist proposals to promote such benefits. Coalter (2007) in his research around 'the active citizen' references previous UK government initiatives that did go so far to suggest that:

"Participation in the arts and sport has a beneficial social impact. Arts and sport are inclusive and can contribute to neighbourhood renewal. They can build confidence and encourage strong community groups."

It can also be argued that both practices share a commonality of approaches, although examples of shared philosophies are also scarce. A number of projects highlighted through this paper evidence how collaboration can foster new forms of hybrid practice for consumers, participants and producers. Social challenges can be addressed through rich partnerships across sport and cultural organisations. New approaches to both disciplines are possible by developing communities of practice, such as the Fields of Vision, that endeavour to promote cultural citizenship. This necessitates the forming of communities of interested parties, who will promote the value of cross-discipline working. It is possible that arts and sport can change the perception of each other and communicate with differing audiences, while opening up new spaces for cultural production engaging with activities that focus on the body.

\section{Literature Review: Sport into Art}

In contemporary writing around the potential to draw together sport and art, the aesthetic of sport is a prominent feature in attempts to draw similarities between the two. However, the lack of competition, perceived as existing within the arts, is also stated as a particular difference. It could be said that within visual art specifically the notion of competition exists in many forms, such as competitive processes for artistic commissions, funding, exhibitions, prizes and projects, many of which have a jury attached to them who are tasked with judging entries on a range of criteria. ${ }^{5}$

\footnotetext{
${ }^{4}$ Case studies from this period are discussed later in the paper. To note also the 2012 UK Cultural Olympiad had a total funding of $£ 126.6$ million, included 40,000 artists and 5,370 new works produced.

${ }^{5}$ Notably in the US the competitions and exhibition call outs are called juried exhibitions.
} 
In terms of visual art, contemporary artists have shown an increasing interest in sport(s) ranging from a focus on the body aesthetic, performance, endurance, movement, the architecture and spaces of sport and the increasing media coverage.

In the 2002 Body Power/Power Play: Views on Sports in Contemporary Arts contemporary art exhibition in Stuggart, Germany organized as part of Stuggart's proposal for the 2012 Olympic Games, the catalogue introduction by Andrea Jahn notes:

"In my search for texts on sports and art, I began to suspect at some point that, at least since the 1990's the relationship between the two was one of mutual scepticism or lack of interest." (Jahn 2002)

There are notable exceptions to this statement through examples of creative practitioners who have undertaken residencies and produced work challenging and responding to sport. Recent examples include Julien Previeux's Petite de la triche (2015) installation for the 2015 Lyon Biennale, France. The installation discussed the relationship between sport and technological advancement and the impact this has in the design of objects and the role in which the media played in the subsequent banning of certain equipment. The Speedo Fastskin features as once of the (banned from 2010 in swimming events) curated objects, its technological advancement resulted in 29 world records being broken in the space of 5 days of the 2009 Rome FINA Swimming Championships and was deemed by journalists as 'technology doping' (McCullough 2010).

Martin Creed's well publicised piece Work No. 850 (2008) involved an athlete running through the Tate Gallery, London every thirty seconds as fast as possible followed by a pause. Here running literally becomes art as the audience, who now appear on the sidelines, are exposed to the sheer physicality of the relentless act in an unlikely neoclassical gallery setting. It is at odds with the space, as running is usually prohibited in galleries. Interestingly Puma collaborated with Creed in supplying the apparel for the runners and this branding is promoted through the media exposure of the project.

It is when notions of performance are utilised that the boundaries seem to dissolve between arts and sport. Dutch performance artist Guido Van der Werve undertakes feats of running and triathlon endurance and documents them via film. Number Thirteen: Home (similar to Creed he numbers his works) (2008) is the film documentary of a 1200 mile triathlon he undertook. Here we see sport as art, the experience and subsequent documentation of the experience is the creative outcome.

Philippe Parreno and Douglas Gordon's film Zidane: A $21^{\text {st }}$ Century Portrait (2006) is perhaps the most widely exhibited work of contemporary art that focusses on sport as it's subject. A documentary film about Zidane during one football match, which only focusses intently on him (and not the game) it is a mesmerizing contemporary portrait. It has been shown internationally at film festivals, as well as in gallery settings. It is perhaps not surprising that in surveying the landscape of sport and art exemplars it is the subject of football that features most prominently. Futbol: The Beautifil Game was a group 
exhibition (timed in relation to the World Cup of that year) of thirty established (high profile) artists at The Los Angeles County Museum of Art in and mass spectacle as well as the shared human experience between diverse spectators. Sport in Art was also a large a group exhibition in 2012 at The Museum of Art of Kracow included 40 artists across a broad range of media, from illustration to conceptually dense contemporary art.

One final example is that of L'Entorse, E(x)sports project. An extensive festival that previously created biennale projects linking arts and sport in France and provided the opportunity for the practitioners of each to work together within local French communities and also overseas in the UK. The project ran over a period of 5 years and promoted the working together of arts and sports community organisations in the UK and France.

\section{Literature Review: Art into Sport}

Sport, as a media event and leisure ritual, is increasingly becoming a center of commercial and personal interest, with an ever-greater role in society, politics, and the economy (Jahn 2002).

Sport is becoming increasingly popular in the UK with a record number of individuals taking part in amateur sports. The notion of sport itself is continually expanding and like art, its boundaries and definitions are becoming increasingly blurry and pleasingly difficult to define. As Platchias (2003) writes:

"Both art and sport appear to be open concepts in that they are unamenable to an absolute definition."

In Welsch's (2006) article discussing the possibility of sport being art he states in the introduction that:

"...the modern transformations of the concept of art in particular allow sport's to be viewed as art.." (Welsch 2006)

He continues to describe the move within sport from ethics to aesthetics. This view that might rely on aesthetics as a common element can be seen as limited however, and it is arts continued challenge and use of the everyday experience that makes a real connection between the two disciplines. While Welsch (2006) claims that "...sport is distant from ordinary life". This notion is, however, increasingly contested, particularly with the growth of mass participation events and the rise of the 'amateur', alongside the boundaries of what is now considered sport being progressively more stretched ${ }^{6}$.

Stephanie Merchant also writes about the rise of the aesthetic experience in sport in her article that refers to 'glow sport'. Glow sports are (usually) night time mass participation spectacle based running events, whereby lights, paint

\footnotetext{
${ }^{6}$ The contemporary rise of 'esports' being an example in case, while located in videogame culture is increasingly referred to as a 'sport'.
} 
and other glow in the dark apparatus are used to navigate and create an apparently unique visual and physical experience.

"As the boundary between sport and leisure becomes increasingly blurry over time, we see a new branch of sporting events that not only facilitate the human expression of sporting skill, endurance, competition and speed but they also foreground and play with the ways in which spatial perception, experience, and in particular sensory experience contribute to arguably a more memorable, interesting, in short 'sensational' event experience." (Merchant 2017)

Linked to the aesthetic lure of 'glow sports' one of the most widely reviewed pieces of art inspired by the UK's Yorkshire staging in 2014 of The Tour De France was Ghost Peleton (2014) by Phoenix Dance Theatre and NVA, which focused on night time use of light and human movement, yet the piece was created by an arts organization with sport as it's subject. The cultural activities surrounding the Tour De Yorkshire cycle race were known under the umbrella title of The Grand Depart. This was intended to be a smaller-scale approach to a cultural Olympiad ahead of the Tour de France arriving in Yorkshire and Ghost Peleton formed part of The Grand Depart, alongside a series of other cycling inspired artworks. In a similar way to Merchant's descriptions, the success of the piece lay in its spectacle, with an emphasis on the aesthetics (and actually the resulting seductive photography documenting the piece). The piece involved a film and live performance with both dancers and cyclists. The cyclists were photographed and filmed travelled along some of the Tour De France (Yorkshire) route at night illuminated by wearing special NVA LED designed suits that changed colour depending on the speed and movement of the rider.

The use of aesthetics and the seductive draw of such innovative approaches to movement are limited to the visual in this example and participation for an audience is largely in many ways passive. There is potential for new knowledge through arts and sport collaboration that goes deeper than the visual via a shared theoretical base and in particular precedents in philosophy, sociology, history and culture.

Models of theory that cross the disciplines of visual arts and sport can also often focus on human performance and movement. In some ways this can be an unconscious connection, as is the case in contemporary art with works created under the umbrella of Endurance Performance Art. An obvious example would be the endurance performance art of Marina Abramovic, whose artwork seeks to test the limits of physical endurance. Abramovic's work has been prominent since the early 1970's and her 2010 piece The Artist is Present at the Museum of Modern Art New York was widely publicized due to the public performance which saw the artist sit still and silent for a period of 800 hours in the public gallery. Here philosophical notions of human endurance could be suggested as a common ground across arts and sport, although they are not articulated deliberately in this way and it is the author here who is drawing these parallels.

There are abundant examples across the broad spectrum of the arts where sport is the chosen topic. This is not surprisingly, more prevalent than any other 
area in literature, both fiction and non-fiction. One unexpected piece that stands out is the well-known fiction writer Joyce Carol Oates writing eloquently around the topic of boxing and drawing similarities with theatre in her collection of essays On Boxing:

"Each boxing match is a story - a unique and highly compressed drama without words." (Oates 2006)

Oates goes on to state that the boxer is on the stage of a ring in an act of a very public performance to demonstrate their limits physically and psychologically with the audience as vouyeurs of a kind entwined in an intimate spectacle. Interestingly Oates also writes as a runner herself around the concept of running and its relationship with the arts:

"In running, spirit seems to pervade the body; as musicians experience the uncanny phenomenon of tissue memory in their fingertips, so the runner seems to experience in feet, lungs, quickened heartbeat, an extension of the imagining self." (Oates 1999)

One final example of the artist as sportsperson and the links between the two that a practitioner can embody is bought poetically alive in Haruki Murakami's book What I Talk About When I Talk about Running (2009). A personal memoir that links his writing practice to the practice of running alongside a reflection on ageing, the book reads like a graceful honest piece of wandering prose.

\section{Findings: Transformative Models of Arts and Sports}

The following case studies involving sport and arts aim to evidence impact beyond only being directly involved in the physical activity. They also seek to extend the boundaries of what might be considered 'sport' and 'arts'.

"...while ethnographic research has generated important insights about embodiment, sport and movement cultures, there is a danger that the underlying message is that one needs to do the activity to fully understand it." (Sparkes 2017)

The RUN RUN RUN Biennale was an interdisciplinary programme initiated by Kai Syng Tan (2019), exploring the ways in which running could be activated as a creative material, metaphor and methodology to think through critical issues related to the body, gender, space and community. With versions of the festival from 2014 - 2018 the biennale has focussed on running as a 'tool' (an artistic one) in which considerations surrounding the body and human movement can be analysed through a lens of running activity. While there currently exists areas of research termed Running Studies within the discourse of the social sciences, the RUN RUN RUN founder noticed that there was a gap in the study of running outside this and certainly in the area of the arts and running ${ }^{7}$. Tan's programme

\footnotetext{
${ }^{7}$ The work of Bale (2004) Running Cultures: Racing in Time and Space does seek to extend this
} 
however was distinct in that it was aimed at examining running as an arts and humanities discourse in its own right. The events and seminars that have formed part of RUN RUN RUN have been hugely successful at drawing speakers and practitioners across arts, humanities and sports and from over 30 different institutions.

Where the physical experience can be translated into creative output to further engage other participants and audiences (other than those taking part in the physical activity) there is a real opportunity for participants to reconsider their relationship with concepts of the body, community, environment and movement in a multi-faceted way. This approach is referred to by Froggart (2016) as a 'third space' that is importantly termed, 'transformative'.

"Art and sport are brought into a creatively unstable interaction with each other. A third space emerges in which each transforms the other in participant experience giving rise to new cultural experience." (Froggart 2016)

This description is situated around Froggart's discussion of the Seaswim project (2011 onwards) which formed part of the I-move Cultural Olympiad programme for the UK 2012 Olympics. I-Move was the county of Yorkshire's Cultural Olympiad programme and Froggart and her team have undertaken an evaluation of the post-games impact of the arts activities that formed this.

"The initial aims of I-move clearly stated that its intentions were to ...explore and transform people's relationship to their bodies through movement and shift the relationship between society and the moving body." (Froggart 2016)

The move to expand the notion of sport to 'movement' resulted in a broader approach to the artistic projects. Froggart describes the different models of participation in a number of selected I-move projects and discusses how they encouraged different modes of experience across both arts and sport. In her first example she describes the Additive approach. The creative work being an "add on" or added to an event, such as an exhibition accompanying a sports event. Secondly, she refers to Interactive, sport usually being the subject matter with an interaction taking place between arts and sport and in some cases methods and practice being interchanged between the two disciplines (Most examples cited in this paper up to this point would be situated in this category). Finally, she uses Seaswim as an example of a Transformative approach. Where the space is not sport or art and cannot be classed as either - but is a new third space with real integration and interaction that defies the discipline boundaries. The transformative space can give rise to new experiences for the participants and potentially offers expanded opportunities for participants to shape experiences.

discourse and draws references from literature, poetry film and art. 
Figure 1. Lynne Froggart's Models of Participation in Arts and Sport (Seaswim)

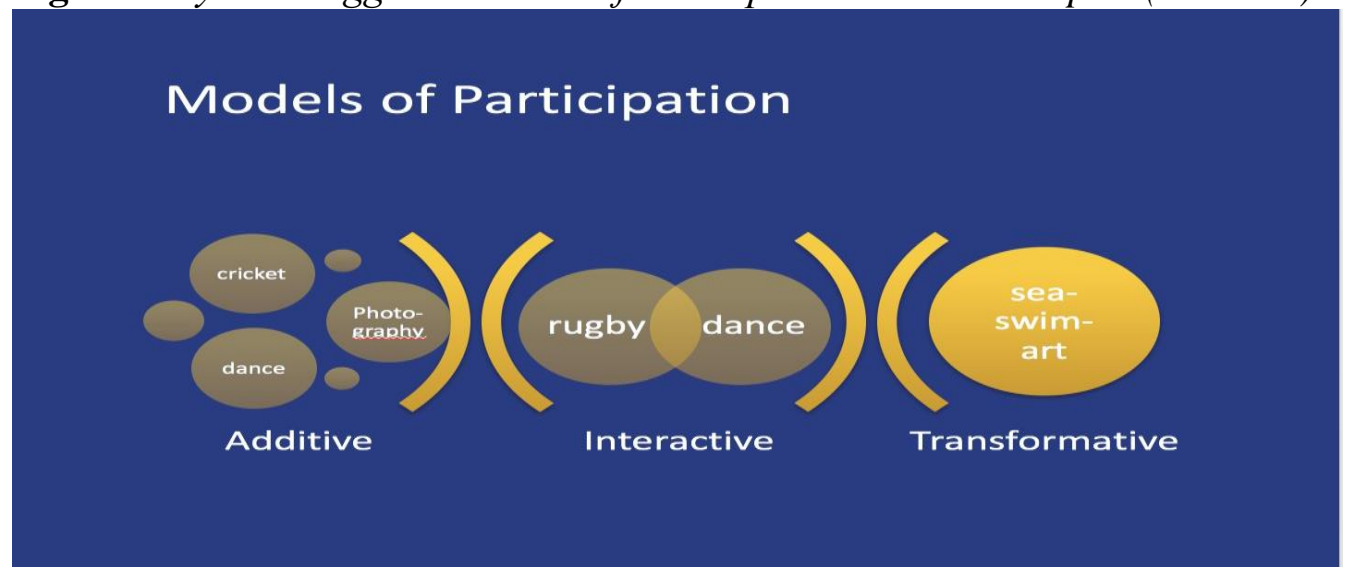

Source: Froggart (2016) Fields of Vision Seminar Presentation.

Froggart's diagram (Figure 1) above illustrates the methods that the I-move projects employed and how each arts and sport interaction led to a different level of participation from an audience and ultimately led to a variety of crossdisciplinary approaches (diagram). The Seaswim (2011 onwards) was a locally grown project that had a strong sense of place through its base on Scarborough beach on the North East coast of the UK. It explored the relationship between swimming in the sea and creativity. A number of works produced involved the act of swimming in the production of work. Situated around organised public swims, workshops in beach huts, performances and artist residencies it was open to all abilities and ages. It altered local people's perceptions of their environment by a direct experience with it followed by opportunities to be creative based on the physical and mental experience of the sea, which participants often described as 'liberating' highlighting the transformative effects of sea swimming, a sport which was often new to participants.

\section{Fields of Vision: Propositions}

In the UK currently art and sport are being marginalised in the school curriculum. In a school curriculum that has a focus on testing from year two in reading, punctuation, spelling and maths, Physical Education and the Creative Disciplines are seeing their subjects emphasis and time allocated shrinking. The proportion of 15 and 16 year old pupils in secondary school in the UK selecting art music and drama has fallen to its lowest in 10 years (Guardian 2018) alongside this secondary schools have reduced teaching time and resources for physical education drastically over the last five years (Hazel 2018). As such this is having an impact on the number of students wanting to pursue creative and sporting subjects at University and ultimately within the UK after graduation.

There are clear benefits to drawing connections across the two disciplines. Collaboration can result in a higher participation rate in both and innovative projects can encourage an engagement within communities that is meaningful and long lasting. In the Fields of Vision project Jonathan Long writes: 
"The (UK) government invests in sport and the arts not just for their own sake, but for the very similar social roles they are expected to play. Nevertheless, collaboration and partnership, never mind synthesis, do not come easy." (Long 2017)

Fields of Vision is a grouping of researchers, academics, policymakers, cultural producers, artists and sports people interested in the relationship between the arts and sport. Fields of Vision was conceived in 2011 by Doug Sandle, then the Chair of Leeds Rugby Arts and initially developed in partnership with Jonathan Long of the Research Institute for Sport, Physical Activity and Leisure of Leeds Beckett University and later formed into a more expansive Steering Group with members Franco Bianchini and Lisa Stansbie.

"Through a network of individuals and organisations Fields of Vision aims to encourage collaboration between the two fields by developing the arts to express and critique sport, to highlight sport as a source of creativity in arts practice, to encourage sporting organisations and teams to use the arts in their community work and as a means to address social and cultural issues within sport." (Sandle 2018)

The original 2012 International Conference Fields of Vision (which subsequently started the development of a group of interested parties) was conceived and organized to coincide with the year of the Olympics staged in the UK and took place in November 2012. Convened by Leeds Rugby Arts (Leeds Rugby Foundation) and hosted in association with Leeds Beckett University its intentions were to bring together those interested or engaged in the historical and contemporary relationship between the arts and sport, and to facilitate interdisciplinary partnerships. In holding the event at the end of a four-year cultural Olympiad, it could situate itself as a timely review of the activities that had taken place as part of the cultural Olympiad and propose methods in which these approaches might be utilised in the future. The conference attracted academics, researchers, arts practitioners, cultural producers and policy-makers and also resulted in a series of new artworks, established through a Fields of Vision Arts Programme supported by the Arts Council England. Papers and creative practice presented at the conference also resulted in the 2014 book Fields of Vision: The Arts in Sport.

Building on this previous work the $\mathrm{AHRC}^{8}$ funded Fields of Vision Seminar Series $(2015$ - 2017) was a project intended to expand the conversation around arts and sport across the UK and include opportunities to discuss key themes such as Participation and Audiences, Aesthetics and Representation and Well-being, social capital and cultural citizenship, all of which resulted in the publication of an arts and sport manifesto. Three seminars took place at The National Football Museum, Manchester, Headingley Carnegie Stadium, Leeds and The Watershed, Bristol. Ensuring the seminar reflected its topic, the venues were a combination of sports and arts venues. While some of the seminar presenters were also involved in the initial 2012 conference, they were able to critically evaluate their experiences

\footnotetext{
${ }^{8} \mathrm{AHRC}$ is the UK Arts and Humanities Research Council. It provides funding for arts and humanities research and postgraduate study.
} 
since 2012, and in some cases review the legacy and social impact of the work undertaken as part of the cultural Olympiad. In particular Beatriz Garcia talked about her London 2012 Cultural Olympiad Evaluation (2013) and her publication Reflections on the 2012 Cultural Olympiad and London 2012 Festival (2013). It also provided a platform to foster opportunities to collaborate across institutions and disciplines and potentially create new and emerging area of research.

It could be said that Fields of Vision in itself is a community of practice with an identified shared commitment to the arts and sport. A group sharing an interest in bringing the two disciplines together and learning through their network and relationship building how the links between the two can be improved, fostered and expanded.

\section{Conclusions}

According to Beatriz (2013) the 2012 UK Cultural Olympiad resulted in 10,940 new partnerships being formed as a result of the program. This included partnerships and collaboration across cultural organisations, businesses, educational establishments, local authorities and sports organisations. This could suggest that where there is a strong focus on programming backed by largescale funding it is possible to draw different collaborations together. It should also be stated that this included a broad range of art forms. However, keeping this momentum is difficult as $30 \%$ of organisations also stated that they would be keen to continue the work they had established as part of the Cultural Olympiad but it would be dependent on funding.

In 2016, for the first time, The International Olympic Committee itself commissioned three artists to be artist in residence in Rio during the Olympic Games 2016. They stated the importance of doing this by quoting the original aspirations of the Olympic Movement. For the Rio 2016 Cultural Olympiad it was clear that Brazil did not have the funding to support a cultural Olympiad and artistic events were as a result more spontaneous and largely took place at a local level with during the games itself, led by community arts groups. Perhaps this needs consideration for the future in terms of reflecting the aspirations and needs of the host city and it's communities.

"A Cultural Olympiad, driven by the host city and country (while inspired and open to the contributions of the broader Olympic Movement) continues to be essential as a counterpoint to the sporting competitions and should keep growing and developing in future Games editions. All the same, having the IOC directly involved as a commissioner of art sets an excellent precedent to raise expectations and make everyone aware that this is central - not tangential - to the Olympic mission." (Garcia 2016)

It is clear that the support for arts and sports initiatives linked to world sporting events and even at local level is connected to funding streams. In order to raise the appetite for initiatives it would need arts and sports organisations and 
policy makers willingness to collaborate and lobby for funding and support for joint projects.

In a report undertaken in Scotland by Glasgow Life Services (Jubb and Cutherbert 2014) Running and Cultural Participation, the participation of deprived communities within the Glasgow's well known running events and cultural organisations was analysed with a view to increasing the uptake in both, with a hope this might impact on wellbeing. The report suggests that access to both needs to improve and in particular the confidence of community participants who felt that cultural and sport offers were not aimed at them. Interestingly the report is split into two distinct sections - the cultural offer and the running study.

The Fields of Vision Manifesto was developed to overcome divisions and provide a proposal to bring together individuals, organisations and policy makers. The use of the term manifesto was particular, in that it was aimed to be a declaration of intentions for new possibilities and a call for action from arts and sports organisations. The manifesto sought to state that sport and art both offer potential to express cultural identity, encourage cultural experimentation and innovation. The collaboration of both can disrupt the dominate parameters of what each discipline is and offer inspirational forms of movement and spectacle. A new third space that might emerge could encourage new and different audiences spanning divides in society, while being built within local communities using familiar environments in new and unexpected ways.

Professor Jonathan Long (2017), of Leeds Beckett's Carnegie School of Sport, said in describing the intentions of the manifesto:

"We want to challenge people not to see 'sport' and 'art' in separate boxes, but to think about the exciting, magical things that could happen by bringing them together. We hope others will share and endorse the Fields of Vision manifesto."

The Fields of Vision manifesto was intended to bridge the gap that currently exists and start a conversation around new opportunities. It was a particular stance that poses moving beyond the Cultural Olympiad model whereby art and sport coexist as part of a mega event and develop truly innovative models of practice that have the potential to address community need. It was aimed at being the start of a longer-term conversation.

The Fields of Vision Manifesto states:

We call upon arts and sports organisations and their communities to pursue these potential benefits through a range of positive actions:

- creating a dialogue to explore collaboration and recognise that the search for new participants/audiences will be assisted by new hybrid forms/ practices

- ensuring that cultural policies incorporate sport, and more generally all strategies for sport and the arts should acknowledge the other 
- co-locating activities to encourage dialogue between arts, sports and other related bodies

- supporting integration not just of form, but also of provision, e.g. where community projects do not offer only sports or only arts, but can provide either as appropriate in the interest of securing community development

- ensuring that where 'partnerships' are established to address community need there is an expectation that both sport and the arts will be represented and that funding will follow

- funding organisations beyond sport and the arts to run initiatives as it is they who are often more open to ideas of integration and hybridity

- experimenting with sports-arts collaboration projects in the programmes of major festivals

- planning for the longer term not just short term ('demonstration') initiatives.

Finally, it could be said that we don't need to redefine the arts or sports or attempt to place boundaries around what each discipline is, but a third space could emerge... a new way of doing and being.

\section{References}

Bale J (2004) Running Cultures: Racing in Time and Space. London: Routledge.

Coalter F (2007) A Wider Social Role for Sport: Who's Keeping the Score? London: Routledge.

Department for Culture Media and Sport (DCMS) (2016) The Culture White Paper. Available at: https://bit.ly/2BmSdFd.

Fields of Vision: Arts and Sport (2017) Fields of Vision Manifesto. Available at: https:// artsinsport.wordpress.com/a-manifesto-for-the-arts-and-sport-together/.

Froggart L (2016) Participant Experience in Art-Sport: Additive, Interactive Transformative? Fields of Vision Seminar Presentation Bristol Manchester 28 June 2016 National Museum of Football. Available at: https://artsinsport.wordpress.com/ resources/.

Garcia B (2013) The Olympic Games and Cultural Policy. London: Routledge.

Garcia B (2016) Olympic Artists in Residence. Available at: http://www.culturalolym pics.org.uk/2016/08/olympic-artists-in-residence/.

The Guardian 2018. Secret Teacher: Subjects Like Art are being Sidelined - but they Matter. Available at: https://bit.ly/2CR4a9N.

Hazel W (2018) PE 'Spiralling Downward' as a Quarter of Secondaries Cut Classes in The Times Education Supplement 16 February 2018. Available at: https://bit.ly/34a OKaf.

Jahn A (2002) Body Power Power Play: Views on Sport in Contemporary Art. Stuggart: Hatje Cantz.

Jubb A and, Cutherbert M (2014) Running and Cultural Participation the Social Marketing Gateway, Glasgow. Available at: https://bit.ly/2zqICwu.

Long J (2017) Cycling Pianos, BMX Dancing and Poetic Swimming: Sport and the Arts Belong Together in The Conversation August 2017. Available at: https://bit.ly/2L2O 5As. 
McCullough S (2010) Body Like a Rocket: Performing Technologies of Naturalization in Third Space: A Journal of Feminist Theory and Culture Vol 9: 2. Available at: https://pdfs.semanticscholar.org/6893/e61e0312d0bcfc2e197cf0f820447870672c.pdf

Merchant S (2017) Glowsport: Re-configuring perception of space in sport and leisure practice. In AC Sparkes (ed) Seeking the Senses in Physical Culture (2017). Oxon: Routledge.

Murakami H (2009) What I Talk About When I Talk About Running. London: Vintage.

Neuendorf H (2016) Painting for Gold Medlas: When Art was an Olympic Discipline. Available at: https://news.artnet.com/art-world/early-olympics-art-events-594437.

Oates JC (1999) Writers on Writing. The New York Times. Available at: https://www.nyti mes.com/1999/07/19/arts/to-invigorate-literary-mind-start-moving-literary-feet.html

Oates JC (2006) On Boxing. New York: Harper Perennial Edition.

Platchias D (2003) Sport is art. The European Journal of Sport Science 3(4): 118. DOI: $10.1080 / 17461390300073403$.

Sandle D (2018) Interview with Lisa Stansbie. December 172018.

Sparkes AC (2017) Seeking the Senses in Physical Culture: Sensuous Scholarship in Action. London: Routledge.

Syng Tan K (2019) An exploration of running as metaphor, methodology, material through the RUN! RUN! RUN! Biennale \#r3fest 2016. Sport in Society 22(5): 829845. DOI: 10.1080/17430437.2018.1430488.

Welsch W (2006) Sport Viewed Aesthetically - And Even as Art. Filosovski Vestnik online/Open: Humanities Press. Available at: https://ojs.zrc-sazu.si/filozofski-vestnik /article/viewFile/4076/3783. 